\title{
FOURIER COSINE-LAPLACE GENERALIZED CONVOLUTION INEQUALITIES AND APPLICATIONS
}

\author{
Nguyen Xuan Thao and Le Xuan Huy
}

Abstract. We introduce several weighted $L_{p}\left(\mathbb{R}_{+}\right)$-norm inequalities and integral transform related to the generalized convolution with a weight function for the Fourier cosine and Laplace transforms. Some applications of these inequalities to estimate the solutions of some partial differential equations are considered. We also obtained solutions of a class of the Toeplitz plus Hankel integro-differential equations in closed form.

Mathematics subject classification (2010): 33C10, 44A35, 45E10, 45J05, 47A30, 47B15.

Keywords and phrases: Laplace transform, Fourier cosine transform, convolution, convolution inequality, integro-differential equation.

\section{REFERENCES}

[1] E. C. Titchmarch, Introduction the Theory of Fourier Intergrals, Third Edition. Chelsea Publishing Co., New York, 1986.

[2] E. M. Stein And G. Weiss, Introduction to Fourier Analysis on Euclidean Spaces, Princeton University Press, 1971.

[3] Beteman And A. ERdelyi, Table of Integral Transforms, New York-Toronto, McGraw-Hill Book Company, Inc, 1954.

[4] I. N. SNEDdon, Fourier Transforms, McGray-Hill, New York, 1951.

[5] L. Debnath, D. Bhatta, Integral Transforms and Their Applications, Chapman and Hall/CRC, Boca Raton, 2007.

[6] N. D. V. Nhan, D. T. Duc, Fundamental inequalities for the iterated Laplace convolution in weighted $L_{p}$ spaces and their applications, Integral Transforms and Special Functions 19, 9-10 (2008), 655-664.

[7] N. X. Thao, T. TuAn And L. X. HuY, The Fourier-Laplace generalized convolutions and applications to integral equations, 41, (2013), 451-464.

[8] S. Saitoh, Weighted $L_{p}$-norm inequalities in convolution, Survey on Classical Inequalities 571, (2000), 225-234.

[9] S. Saitoh, V. K. TUAN AND M. YAmamoto, Reverse weighted $L_{p}$-norm inequalities in convolutions, Journal of Inequalities in Pure and Applied Mathematics 1, 1 (2000), Article 7. [online: http://jipam.vu.edu.au/v1n1/018-99.html].

[10] S. SAitoh, V. K. TuAn AND M. YAmAmoto, Reverse convolution inequalities and applications to inverse heat source problems, Journal of Inequalities in Pure and Applied Mathematics 3, 5, (2002), 1-11, Article 80.

[11] V. K. TUAN, Integral transforms of Fourier cosine convolution type, Journal of Mathematical Analysis and Applications 229, 2 (1999), 519-529. 